\title{
PNLD: Trajetória da política pública educacional do PNLD Campo no Brasil
}

\author{
PNLD: Trajectory of the public educational policy \\ Of the rural PNLD in Brazil
}

\author{
Nayara Figueira $^{1 *}$, Francis Mary Guimarães Nogueira ${ }^{1}$
}

\begin{abstract}
RESUMO
O presente artigo busca sintetizar a implementação do Programa Nacional do Livro e do Material Didático (PNLD), assumindo a Educação do Campo como objetivo de estudo. Compreendendo-a não apenas como modalidade de ensino, mas também como uma política pública que garanta a população camponesa os mesmos direitos educacionais da população citadina, dá-se ênfase às discussões do Programa Nacional do Livro Didático do Campo (PNLD CAMPO). Assim, faz-se a defesa da qualidade de ensino para o povo camponês, associado às discussões e análise do PNLD CAMPO. Este artigo é resultado de parte de uma dissertação de mestrado e baseia-se em produções científicas do portal de periódicos-CAPES/MEC, da Biblioteca Digital Brasileira de Teses e Dissertações - BDTD, análise de documentos oficiais desse programa de governo, bem como as leis que o amparam, para auxiliar na análises propostas. Aponta-se ao final das discussões, o negligenciamento ao campesinato no conjunto das políticas públicas da educação brasileira, relacionado ao encerramento do programa que é direcionado especificamente a Educação do Campo.
\end{abstract}

Palavras-chave: PNLD Campo; Livro didático; Educação do Campo; Política Educacional; Movimentos de Luta pela Terra;

\begin{abstract}
The present article seeks to synthesize the implementation of the National Program of Books and Didactic Material (PNLD), taking Field Education as the study objective. Understanding it not only as a teaching modality, but also as a public policy that guarantees the peasant population the same educational rights as the urban population, emphasis is given to the discussions of the National Program of the Rural Textbook (PNLD CAMPO). Thus, we defend the quality of education for the peasant population, associated with the discussions and analysis of the PNLD CAMPO. This article is the result of part of a master's thesis and is based on scientific production of the periodical portal-CAPES/MEC, the Brazilian Digital Library of Theses and Dissertations - BDTD, analysis of official documents of this government program, as well as the laws that support it, to assist in the proposed analysis. At the end of the discussions, it is pointed out the neglect of the peasantry in the set of public policies of Brazilian education, related to the closure of the program that is specifically directed to Rural Education.
\end{abstract}

Keywords: PNLD Campo; Textbook; Rural Education; Educational Policy; Land Struggle Movements;

\footnotetext{
${ }^{1}$ Universidade Estadual Do Oeste Do Paraná - Unioeste. *professora.nayara@hotmail.com
} 


\section{INTRODUÇÃO}

A educação é uma política pública social de responsabilidade do Estado, porém o histórico de implementação de políticas educacionais é permeado de muita luta por parte da população, que apresenta suas demandas e pressiona o Estado para atendê-las.

A diversidade sociocultural da população brasileira é extensa, e no campo ela se apresenta por meio da relação dos indivíduos com o manejo da terra e da água. É representada, segundo Caldart (2008), por "pequenos agricultores, quilombolas, indígenas, pescadores, camponeses, assentados, reassentados, ribeirinhos, povos da floresta, caipiras, lavradores, roceiros, sem-terra, caboclos, agregados, meeiros, boiasfrias, e outros grupos mais".

Em relação a educação destinada as populações campesinas, apesar das lutas dos movimentos sociais que os defendem e aparentes incentivos governamentais, a Educação do Campo continua sendo tratada com inferioridade, sendo sujeita a educação de um modelo citadino, que é visto como prioridade das políticas públicas e dos governos, contrariando o que preconiza o artigo 205 da Constituição Federal de 1988, ao determinar que a educação seja um direito social, garantido a todos indivíduos, com igualdade de condições para o acesso e permanência na escola.

As Diretrizes Curriculares da Educação do Campo, retratam a subordinação do campo à cidade no viés das políticas públicas:

\footnotetext{
A educação do campo tem sido historicamente marginalizada na construção de políticas públicas. Tratada como política compensatória, suas demandas e sua especificidade raramente têm sido objeto de pesquisa no espaço da academia e na formulação de currículos nos diferentes níveis e modalidades de ensino. A educação para os povos do campo é trabalhado a partir de um currículo essencialmente urbano e, quase sempre, deslocado das necessidades e da realidade do campo. (PARANÁ, 2006, p. 25).
}

Para Caldart (2008), A Educação do Campo nasce dessa pressão de movimentos sociais por uma política educacional para comunidades camponesas, provém das lutas dos sem-terra pela implantação de escolas públicas "nas áreas de reforma agrária com as lutas de resistência de inúmeras organizações e comunidades camponesas para não perder 
suas escolas, suas experiências de educação, suas comunidades, seu território, sua identidade" (CALDART, 2008, p.71).

Neste sentido, Berbat e Feijó (2016, p. 479), destacam que "a Educação do Campo pode ser entendida como a articulação entre a luta por um modelo de desenvolvimento compatível com a vida digna no campo e o acesso à educação de qualidade que atenda a essas demandas". Assim sendo, a Educação do Campo reflete os interesses da classe trabalhadora em favor de uma educação de qualidade para a formação integral da população do campo, estando articulada aos processos culturais e sociais vividos pelos trabalhadores em suas lutas diárias.

Essa articulação do cotidiano dos alunos da zona rural e de suas vivências nos processos de ensino e aprendizagem tem sido norteadora das políticas públicas do governo, dentre elas a produção e distribuição de livros didáticos específicos para o campo.

O Programa Nacional do Livro Didático do Campo (PNLD Campo), é a materialização da Lei de Diretrizes e Bases da Educação Nacional n 9.394/96, no que diz respeito ao reconhecimento da diversidade do campo, uma vez que determina que os sistemas de ensino promovam as adaptações necessárias às peculiaridades da vida rural, conforme destacado em seus incisos:

I -conteúdos curriculares e metodologias apropriadas às reais necessidades e interesses dos alunos da zona rural; II -organização escolar própria, incluindo adequação do calendário escolar às fases do ciclo agrícola e às condições climáticas; III -adequação à natureza do trabalho na zona rural (BRASIL, 1996, Art.28).

A proposta de estabelecer o livro didático específico para atender o campo e distribuí-los gratuitamente a todos os alunos das escolas públicas do campo, representa uma ação estatal positiva em favor da melhoria da educação pública campesina, principalmente por ser concebida dentro do contexto real de ensino no campo. Porém diante do conflito entre o que foi indicado para ser cumprido nos documentos oficiais e a realidade objetiva do atendimento por meio desse programa, Vieira (2013), destaca que “embora as políticas instituídas incluam demandas sociais vindas de grupos organizados, em geral se apresentam no contexto de uma sociedade capitalista" (VIEIRA, 2013, p. 46). O modelo de escola proposto pelas políticas públicas vinculadas ao capitalismo se 
fundamenta na divisão campo/cidade, na expropriação da terra, dos meios de subsistência e da força de trabalho do camponês.

Considerando essa prerrogativa, o modelo de educação na esfera política, muitas vezes é proposto e realizado a partir das reivindicações dos movimentos que defendem a Educação do Campo, que forçosamente pressionam o Estado a atender suas demandas, porém na prática do programa, encontra-se um projeto de Educação Rural e não de Educação do Campo.

\begin{abstract}
A Educação do Campo nasceu no contraponto à Educação Rural, instituída pelo Estado brasileiro, como linha auxiliar da implantação de um projeto de sociedade e agricultura subordinado aos interesses do capital, que submeteu e pretende continuar submetendo a educação escolar ao objetivo de preparar mão-de- -obra minimamente qualificada e barata, sem perspectiva de um projeto de educação que contribua à emancipação dos camponeses. (FONEC, 2012, p.1-2).
\end{abstract}

É nesse conflito de interesses que a Educação do Campo avança ao mesmo passo que retrocede, pois o Estado concebe os sujeitos do campo apenas como beneficiários da implementação das políticas públicas, mas a luta para que sejam partícipes de todo esse

processo continua. É necessário que se imprima o protagonismo dos sujeitos do campo na elaboração dessas políticas voltadas ao campo.

Tendo em vista as discussões referentes ao programa nacional de distribuição de livros didático específicos para o campo, é indispensável uma breve descrição sobre o livro e sua importância no processo de ensino aprendizagem nas escolas. Antes, porém, adverte-se que o livro é carregado de intencionalidades mutáveis, dependendo do contexto político em que está inserido e do modo como é utilizado. É um instrumento pedagógico que toma diferentes significados ao longo da história, que nem sempre se apresenta por um viés exclusivamente positivo, portanto, cabe revelar de forma sumária, facetas deste material.

\title{
A IMPORTÂNCIA DO LIVRO DIDÁTICO COMO INSTRUMENTO PEDAGÓGICO E O PNLD CAMPO COMO POLÍTICA PÚBLICA
}

O livro didático é um dos instrumentos mais importantes para a formação humana e científica. Esa afirmação se torna ainda mais conspícua dentro da realidade do campo, já que o acesso a outros materiais pedagógicos não chega com tanta facilidade como nas escolas de área urbana. Portanto, analisar o Programa Nacional do Livro Didático do 
Campo, reconhecendo o livro como material fundamental para elevar os índices de desempenho escolar dos camponeses, é resistir a estereótipos de que o ensino no campo é atrasado e inferior e que viver no campo é sinônimo de retrocesso. É propugnar o respeito a singularidade dos povos do campo e sua valorização no âmbito das políticas públicas.

Carneiro e Santos (2006), destacam que o livro didático assume essencialmente três grandes funções:

de informação, de estruturação e organização da aprendizagem e, finalmente, a função de guia do aluno no processo de apreensão do mundo exterior. Deste modo, a última função depende de o livro permitir que aconteça uma interação da experiência do aluno e atividades que instiguem o estudante desenvolver seu próprio conhecimento, ou ao contrário, induzi-lo á repetições ou imitações do real. Entretanto o professor deve estar preparado para fazer uma análise crítica e julgar os méritos do livro que utiliza ou pretende utilizar, assim como para introduzir as devidas correções e/ou adaptações que achar conveniente e necessárias (CARNEIRO; SANTOS, 2006, p. 206).

O livro em sua trajetória, passou por diversos desafios até demonstrar sua importância na vida das pessoas e no desenvolvimento das sociedades. Ganhou os espaços escolares como instrumento de apoio na educação de crianças, jovens e adultos. Promove o crescimento intelectual no ser humano e atua como vetor do conhecimento historicamente acumulado.

Segundo Araújo (2012), A história do livro compreende uma série de inovações realizadas por diversos povos no intuito de gravar o conhecimento e passá-lo de geração em geração.

O mundo não seria o mesmo se os povos não pudessem conhecer as ideias de seus antepassados. [...]Durante a antiguidade, a primeira forma encontrada para gravar o conhecimento foi escrevendo-o em pedra ou tábuas de argila. Após algum tempo, surgiram os khartés, que eram cilindros de folhas de papiro fáceis de transportar. A inovação seguinte foi o pergaminho, que em pouco tempo substituiu o papiro. $\mathrm{O}$ pergaminho era feito com peles de animais (ovelha, cordeiro, carneiro, cabra) e nele era possível escrever com maior facilidade (ARAÚJO, 2012, online).

Para Santos e Martins (2011, p. 21), "ao longo dos anos, o livro didático vem se constituindo em uma ferramenta de caráter pedagógico capaz de provocar e nortear 
possíveis mudanças e aperfeiçoamento na prática pedagógica”. Além de facilitar o planejamento das atividades em sala de aula auxilia os alunos para a aquisição do hábito da leitura, contribui para o desenvolvimento, compreensão e interpretação do conhecimento científico.

Para ser instrumento de aperfeiçoamento pedagógico, o livro didático deve atender às necessidades do aluno; precisa estar vinculado à realidade do espaço históricosocial de sua produção numa perspectiva local e global. De acordo com Libâneo (2002), o livro didático é um recurso importante na escola por ser útil tanto ao professor quanto ao aluno, auxiliando o professor na apresentação do conteúdo e permitindo ao aluno uma forma mais organizada e sistematizada do conhecimento.

Embora não seja o único material de apoio do professor e do aluno, o livro didático ainda é o recurso mais utilizado nas escolas. O acesso a esse material é direito do aluno, garantido pela Lei de Diretrizes e Bases da Educação (LDB), decretos, portarias e resoluções do Ministério da Educação (MEC). Quando bem realizados, os programas de distribuição de livros, promovem a formação de um cidadão autônomo e consciente a diversos aspectos do meio social.

O Fundo Nacional de Desenvolvimento da Educação (FNDE) é a autarquia federal responsável pela execução de várias políticas educacionais do MEC, incluindo o Programa Nacional do Livro e do Material Didático - PNLD.

Segundo dados do FNDE, a trajetória oficial da política do livro didático no Brasil teve início em 1937 com a criação do Instituto Nacional do Livro (INL), por meio do Decreto-Lei $n^{\circ}$ 93, de 21 de dezembro de 1937. Em 1938 - Por meio do Decreto-Lei ${ }^{\circ}$ 1.006, de 30/12/38, é instituída a Comissão Nacional do Livro Didático (CNLD), que estabelece a primeira política de legislação e controle de produção e circulação do livro didático no País. Em 1945, com o Decreto-Lei nº 8.460, de 26/12/45, é consolidada a legislação sobre as condições de produção, importação e utilização do livro didático, restringindo ao professor a escolha do livro a ser utilizado pelos alunos. Em 1966, um acordo entre o Ministério da Educação e a Agência Norte-Americana para o Desenvolvimento Internacional (USAID), permite a criação da Comissão do Livro Técnico e Livro Didático (COLTED), com o objetivo de coordenar as ações referentes à produção, edição e distribuição do livro didático.

Em 1971, o Instituto Nacional do Livro (INL) passa a desenvolver o Programa do Livro Didático para o Ensino Fundamental (Plidef), assumindo as atribuições 
administrativas e de gerenciamento dos recursos financeiros até então a cargo da COLTED. Com a publicação do Decreto ${ }^{\circ} 77.107$, de 4/2/76, o governo assume a compra de boa parcela dos livros para distribuir a parte das escolas e das unidades federadas. Com a extinção do INL, a Fundação Nacional do Material Escolar (Fename) torna-se responsável pela execução do programa do livro didático. Os recursos provêm do Fundo Nacional de Desenvolvimento da Educação (FNDE). Em 1983, em substituição à Fename, é criada a Fundação de Assistência ao Estudante (FAE), que incorpora o Plidef.

Já em 1985, com a edição do Decreto no 91.542, de 19/8/85, o Plidef dá lugar ao Programa Nacional do Livro Didático (PNLD). A partir desse decreto, o PNLD passa a fazer parte da política pública para a educação, com o objetivo principal de adquirir e distribuir, de forma universal e gratuita, livros didáticos para todos os alunos das escolas públicas.

Com a extinção da Fundação de Assistência ao Estudante (FAE), em 1997, a responsabilidade pela política de execução do PNLD é transferida integralmente para o Fundo Nacional de Desenvolvimento da Educação (FNDE).

O PNLD, juntamente com o Programa Nacional Biblioteca da Escola (PNBE), pertenciam ao compêndio dos Programas do Livro (PLi), do governo federal que fornecia as escolas de educação básica pública, obras didáticas, pedagógicas e literárias, bem como com outros materiais de apoio à prática educativa, de forma sistemática, regular e gratuita. Porém, com a publicação do Decreto n ${ }^{\circ}$ 9.099, de 18 de julho de 2017, unificou-se as ações de aquisição e distribuição de livros didáticos e literários, anteriormente contempladas pelo PNLD e PNBE. Com nova nomenclatura, o Programa Nacional do Livro e do Material Didático - PNLD também teve seu escopo ampliado com a possibilidade de inclusão de outros materiais de apoio à prática educativa para além das obras didáticas e literárias: obras pedagógicas, softwares e jogos educacionais, materiais de reforço e correção de fluxo, materiais de formação e materiais destinados à gestão escolar, entre outros.

Destarte, a política de livro didático passou por diversas mudanças até se configurar na política que se tem hoje. Mas é possível perceber também que os livros didáticos para o campo não aparecem na configuração desse programa, isso porque como já mencionado, a Educação do Campo sempre esteve à margem de todas as políticas públicas de educação e para ganhar visibilidade neste cenário, foi necessário que os movimentos sociais organizados, por meio das Conferências, Articulações e Seminários 
nacionais e estaduais da Educação do Campo, se mobilizassem para pressionar o estado a atender essa demanda.

\section{DO PNLD AO PNLD CAMPO}

O PNLD Campo é resultado das reivindicações realizadas pelos Movimentos Sociais em prol de uma educação para os trabalhadores do campo compatível com suas especificidades e fosse valorizada e reconhecida no âmbito das políticas públicas. Nesse viés, os defensores da Educação do Campo, eram contra o Programa Escola Ativa (PEA), programa pioneiro na implementação recursos pedagógicos nas escolas rurais que estimulavam a construção do conhecimento do aluno e da capacitação de professores. Foi implementado no governo de Fernando Henrique Cardoso em 1997, mas o PEA foi oriundo do Programa Escuela Nueva, criado para atender as classes multisseriadas na Colômbia, sob a orientação do Banco Mundial. Sua origem já determinava o fracasso em atender as necessidades do campo, já que é um programa pensado externamente ao campo, e pelas inúmeras pesquisas que demonstraram a ineficácia deste Banco para resolver as questões educativas na América Latina.

No mesmo ano, em 1997, foi realizado o I Encontro Nacional de Educadoras e Educadores da Reforma Agrária (I ENERA), organizado pelo Movimento Sem Terra, que pautou no encontro a luta pela reforma agrária e pelo reconhecimento da identidade própria das escolas do meio rural. Durante este encontro, ocorreu as discussões para a preparação da I Conferência Nacional por uma Educação Básica do Campo.

Esta Conferência aconteceu em Luziânia - GO, em 1998. Reforçava a necessidade da educação para os povos do campo, não ser apenas destinada a eles e sim pensada e produzida com a participação dos camponeses. Diversas entidades ${ }^{2}$, integraram a Conferência para discutir a Educação do Campo à luz da experiência dos povos do campo. A Partir desse momento, a inserção da Educação do Campo na agenda pública foi fortalecida. Demonstrando a força dos Movimentos Sociais nas reivindicações por melhores condições para o campo, no mesmo ano é lançado o Programa Nacional da

\footnotetext{
2 Conferência Nacional dos Bispos do Brasil (CNBB), Movimento dos Trabalhadores Rurais Sem terra (MST), Fundo das Nações Unidas para a Infância (UNICEF), Organização das Nações Unidas para a Educação e Cultura (UNESCO) e a Universidade de Brasília (UnB).
} 
Educação na Reforma Agrária (PRONERA), que só seria reconhecido como política pública em 2010.

A II Conferência Nacional "Por Uma Educação do Campo" ocorre em 2004, com 1.100 participantes, também em Luziânia, GO. O documento de declaração final (versão da plenária), mostra como os movimentos organizados do campo crescem no cenário político em representatividade.

representantes de Movimentos Sociais, Movimento Sindical e Organizações Sociais de Trabalhadores e Trabalhadoras do Campo e da Educação; das Universidades, ONG's e de Centros Familiares de Formação por Alternância; de secretarias estaduais e municipais de educação e de outros órgãos de gestão pública com atuação vinculada à educação e ao campo; trabalhadores/trabalhadoras do campo, educadoras/educadores e educandas/educandos: de comunidades camponesas, ribeirinhas, pesqueiras e extrativistas, de assalariados, quilombolas, povos indígenas (BRASIL, 2004, p.1).

Outros encontros, projetos e espaços foram conquistados pelos Movimentos como legislações específicas, políticas públicas e/ou programas de educação,

as Diretrizes Operacionais da Educação Básica no Campo (DOEBEC) $-\mathrm{n}^{\mathrm{o}} 1$ de 2002; as diretrizes complementares - Resolução $\mathrm{n}^{\mathrm{o}} 2$ de 2008; Programa de Apoio à Formação Superior em Licenciatura em Educação do Campo de 2007 (PROCAMPO) e; o Programa Nacional de Educação do Campo de 2010 (PRONACAMPO) (UEMG, 2014, online).

O entrave no âmbito das políticas públicas pra conquistas como essas é pelos trabalhadores do campo há muitos anos, e assim passaram a se organizar para defender na agenda política a incorporação das demandas do Campo. Sem dúvida, todos os seminários, articulações, conferências e demais organizações das diferentes entidades e sujeitos que lutam pelo direito à educação e por um projeto político pedagógico vinculado aos interesses da classe trabalhadora do campo, foram responsáveis pelas mais diversas conquistas já mencionadas nesse artigo.

Em destaque, o marco de uma importante conquista para o campo, foi o reconhecimento da diversidade sócio-cultural na educação brasileira, por meio do artigo 28 da LDB 9.394/96, que determina aos sistemas de ensino, na oferta de educação básica para a população rural, a promoção das adaptações necessárias à sua adequação às 
peculiaridades da vida rural e de cada região. A partir desse reconhecimento é que foi possível fundamentar-se legalmente para defender o campo e todos que nele vivem.

Sousa e Oliveira (2016, p. 45), destacam que "somente quinze anos após a LDB é que surgiu o primeiro Edital de Convocação para o processo de inscrição e avaliação de obras didáticas, para o Programa Nacional do Livro Didático do Campo", mas somente em 2013 as obras chegaram nas escolas.

Assim, no contexto do PNLD, até 2012, a Educação do Campo, nas séries iniciais do Ensino Fundamental I, permaneceu subordinada ao ensino citadino como historicamente foi, por não ser contemplada por coleções didáticas específicas para as escolas do campo. Para Cruz (2016), a ausência de materiais didáticos condizentes com a realidade do campo, faz com que não se crie mecanismos para valorização da terra e essa falta de representatividade faz aumentar ainda mais a relação de submissão do campesinato frente ao sistema que impõe esse ensino desvinculado com o campo.

\begin{abstract}
A preocupação maior com a adesão dos currículos urbanos em escolas rurais é com a possível formação de alunos alienados perante sua realidade. A formação de alunos que não se identificam como sendo sujeitos do campo e que sobretudo, aceitam sem oferecer resistências as condições impostas pelo sistema de produção capitalista, reproduzindo o discurso do opressor (CRUZ, 2016, p. 443).
\end{abstract}

Em virtude ao exposto, em 2011 é instituído pela da Resolução no 40, de 26/06/2011, o Programa Nacional do Livro Didático para as escolas do campo (PNLD Campo), tendo sua primeira versão e distribuição de livros dois anos depois. Fundamentado na Política de Educação do Campo, o PNLD Campo teve sua primeira edição em 2013, com vistas a atender as escolas pertencentes a áreas rurais, com o objetivo distribuir materiais exclusivos para professores e alunos do campo, visando atender as principais demandas desse contexto específico, qual sejam: classes multisseriadas, apenas um docente para todas as disciplinas, poucos alunos em cada classe, distância da zona urbana, entre outros.

A Instituição do PNLD Campo foi protagonizada pelos trabalhadores do campo e suas organizações, que incidem na política de educação o reconhecimento de seu povo, assim discute-se nas agendas das articulações nacionais e estaduais do campo, a necessidade de disponibilizar material didático que valorize os povos do campo e levem em consideração as especificidades do contexto social, econômico, cultural, político e ambiental do campesinato, como referência para a elaboração de livros didáticos. 
Essa organização dos trabalhadores do campo busca melhores condições de vida, o que inclui a educação. O primeiro guia de livros didáticos para Educação do Campo destaca que:

O Movimento da Educação do Campo é uma ação protagonizada pelos Povos do Campo em torno da luta pelo direito a Educação, que se faz indissociada da luta pela terra, como território de vida e de trabalho. Por meio de suas organizações sociais e sindicais e das organizações criadas no contexto da luta pela Educação do Campo destaca-se o Fórum Nacional da Educação do Campo - FONEC, os Fóruns, Núcleos e Redes Estaduais, Regionais e Locais da Educação do Campo, o trabalho desenvolvido em parceria com Universidades, Movimentos Sociais Sindicais, Organizações Não-Governamentais, Escolas, dentre outros, foram conquistadas as políticas públicas e construíram-se práticas pedagógicas inovadoras, dentre as quais destacamos o PNLD Campo (BRASIL, 2012, p. 10-11).

A SECADI (Secretaria de Educação Continuada, Alfabetização, Diversidade e Inclusão) foi parte fundamental da estrutura necessária para que o campo ganhasse espaço nas políticas públicas. Criada inicialmente como SECAD, é um órgão componente do Ministério da Educação, instituído para atender as demandas em razão de determinadas especificidades com relação as pautas raciais e étnicas, da educação de jovens e adultos e da Educação do Campo. Se torna SECADI em 2011, durante o governo Dilma, quando acrescentou o eixo "inclusão" à SECAD, introduzindo as atribuições antes alocadas na Secretaria de Educação Especial.

Após a Resolução no 40/2011, caberia ao FNDE e a SECADI a elaboração dos editais de convocação, avaliação e seleção dos livros para o PNLD Campo, que se faz sob o Edital de Convocação 05/2011.

O Ministério da Educação, por intermédio da Secretaria de Educação Continuada, Alfabetização, Diversidade e Inclusão (SECADI) e do Fundo Nacional de Desenvolvimento da Educação (FNDE), faz saber aos editores que se encontra aberto o processo de inscrição e avaliação de obras didáticas destinadas aos alunos de escolas públicas que estejam situadas ou mantenham turmas anexas em áreas rurais, que possuam segmentos de aprendizagem, classes multisseriadas ou turmas seriadas dos anos iniciais do ensino fundamental participantes do PNLD (BRASIL, 2011, p. 1). 
Após o primeiro Edital de convocação 05/2011 - CGPLI, as ações do programa foram organizadas por outros documentos que orientariam o processo de escolha das obras didáticas no ano de 2012:

Edital de convocação 05/2011, o Guia de livros didáticos: PNLD Campo 2013; organizado pelo Ministério da Educação, Secretaria de Educação Continuada, Alfabetização, Diversidade e Inclusão, 2012; Carta aos Secretários de Educação e Diretores de Escola do Campo enviada pelo MEC/2012, a Carta Circular 28/2012 COARE/CGPLI/DIRAE/FNDE/MEC, de novembro de 2012 (VIEIRA, 2013, p. 90).

Seguindo as ações de valorização e reconhecimento das especificidades do campesinato brasileiro, é lançado pela SECADI/MEC o Programa Nacional de Educação do Campo (PRONACAMPO), que direciona suas ações ao acesso e a permanência na escola, bem como a valorização do universo cultural das populações do campo. É oficialmente instituído por meio da Portaria $n^{\circ} 86$, no dia 1 de fevereiro de 2013, que define as ações para implantação da política de Educação do Campo.

O programa propõe articular um conjunto de medidas para a melhoria do ensino no campo, das políticas de formação dos professores, produção de material didático e recuperação de infraestrutura na Educação do Campo. Está organizado em quatro eixos de ação: Gestão e Práticas pedagógicas; Formação de Professores; Educação de Jovens e Adultos e Educação Profissional e Tecnológica. No primeiro eixo, estão elencadas ações para a disponibilização de materiais e livros didáticos que atendam a especificidade da população do campo. É a partir desse eixo que o PNLD Campo é desenvolvido. Apesar do PNLD Campo ter sua estrutura baseada no Programa Nacional do Livro e do Material didático (PNLD), que tornou referência para a criação do programa voltado ao campo, suas raízes político-ideológicas são pautadas no Programa Nacional de Educação do Campo (PRONACAMPO).

O programa foi organizado para distribuir as obras didáticas a cada três anos. Ficou vigente durante duas edições (2013-2015; 2016-2018), portanto, as escolas do campo foram atendidas por esse programa somente até 2018, pois no mesmo ano em que iria para sua terceira edição, foi encerrado por meio do Informe $n^{\mathbf{0}}$ 07/2018 COARE/FNDE que trata da seguinte justificativa: "O FNDE informa que, em decorrência de estar em andamento a revisão de marcos legais da educação nacional, não haverá, para 2019, a escolha específica de materiais para atendimento das escolas rurais." Em um cenário de retrocesso, o campesinato brasileiro volta a ser submetido à educação urbana, 
pautada em um contexto de ensino totalmente diferente da realidade vivenciada no campo.

O encerramento do programa, demonstra uma política antagônica as conquistas dos Movimentos da luta pela terra e por uma educação específica para o campo, do governo anterior e do atual, pois a justificativa de estar em andamento os marcos legais da educação nacional, oculta o porquê de apenas a Educação do Campo ser afetada, e nem de que forma esses marcos legais impedem a continuidade do programa. Explicita-se, portanto, o desmonte das políticas dos governos anteriores.

\section{CONSIDERAÇÕES FINAIS}

O livro didático não é o único material de acesso para o conhecimento científico e seu uso não nulifica a necessidade de outros materiais de apoio para enriquecer a prática pedagógica, porém, fica evidente que o livro didático é a fonte mais utilizada nas escolas para auxiliar no processo de ensino-aprendizagem e sua importância não se reduz com a chegada da internet e ou do acesso a outros materiais, por isso, pensar no livro enquanto objeto formador e analisar a via por qual ele chega até as escolas, é fundamental quando se pensa na qualidade de ensino.

Tendo como base a educação do Campo, as principais análises voltam-se para a garantia da particularidade dos trabalhadores do campo nos espaços escolares e nas políticas públicas, o que não vem ocorrendo, visto o encerramento de políticas educacionais voltadas ao campo.

O processo da criação até a implementação do PNLD Campo, não nasceu pelo desejo e espontaneidade do Estado em melhorar a educação destinada aos povos do campo, até porque os índices de fechamento de escolas nesse espaço têm aumentado ano a ano, devido o processo de nucleação de escolas no campo e da falta de políticas públicas de atendimento aos campesinos. O desígnio de todas as conquistas e direitos garantidos à Educação do Campo provém dos próprios trabalhadores do campo e dos movimentos sociais do qual fazem parte, que lutam pelo direito à terra, ao território e à educação que está diretamente vinculada nesse embate, o que representa a busca do bem-estar social e a melhoria das condições de vida. A Educação do Campo é uma conquista permeada por muita luta, e o PNLD Campo se caracterizava como instrumento de garantia da particularidade do povo camponês, porém com seu encerramento, novamente a educação 
do campo fica sem política específica, onde parte do campesinato brasileiro fica submetida à educação urbana, pautada em um contexto de ensino totalmente diferente da realidade vivenciada no campo.

A Escola do Campo necessita ser pensada como parte de um projeto que efetivamente fortaleça os camponeses em suas lutas, portanto, a defesa do PNLD Campo se baseia pelos princípios do programa, como um programa nacional de distribuição de livro didático adequado às classes multisseriadas e às turmas seriadas do campo, para melhor atender às necessidades educacionais desta demanda. Defender a permanência do PNLD Campo, é defender os direitos já conquistados no campo e legitimar a luta de quem busca o reconhecimento da sua identidade e cultura como sinônimo de valoração, é a possibilidade de expressar esse valor combatendo a discriminação sofrida por anos e presente até os dias atuais, que o campo é lugar de atraso e de pessoas rudes e jecas. Por essa razão, o PNLD Campo precisa retornar como política pública, e que os direitos já conquistados na esfera do estado não sejam dissipados "do dia para noite".

Assim, as garantias cada vez menos presente nas políticas educacionais, cabe aos Movimentos Sociais e defensores da Educação do Campo, continuar se mobilizando para a permanência das políticas públicas já conquistas, defendendo a Educação do Campo, reconhecida como projeto de vida e de sociedade.

\section{REFERÊNCIAS}

ARAÚJO, Felipe. A História do livro. Disponível em:http://www.infoescola.com/curiosidades/historia-do-livro/>. Acesso em: 29, jan. de 2021.

BERBAT, Márcio da Costa; FEIJÓ, Gabriela de Carvalho. Diálogos com a Educação do Campo: o livro didático em questão. 2016. Disponível em: https://sistemas.uft.edu.br/periodicos/index.php/campo/article/view/2766. Acesso em: 06 de jun. de 2019.

BRASIL. Decreto no 9.465, de 2 de janeiro de 2019. Aprova a Estrutura Regimental e o Quadro Demonstrativo dos Cargos em Comissão e das Funções de Confiança do Ministério da Educação. Disponível em: https://www.in.gov.br/materia//asset_publisher/Kujrw0TZC2Mb/content/id/57633286. Acesso em: 03, fev. de 2021.

BRASIL. .Decreto no 91.542, de 19/8/85. Institui o Programa Nacional do Livro Didático, dispõe sobre sua execução e dá outras providências. Disponível em: https://www2.camara.leg.br/legin/fed/decret/1980-1987/decreto-91542-19-agosto-1985441959-norma-pe.html.Acesso em: 03, fev. de 2021. 
BRASIL. Constituição Federal do Brasil de 1988. Disponível em: http://www.planalto.gov.br/ccivil_03/Constituicao/Constituicao.htm. acesso em: 07, jan. de 2021.

BRASIL. Decreto no 77.107, de 4/2/76. Dispõe sobre a edição e distribuição de livros textos e dá outras providências.Disponível em:

https://www2.camara.leg.br/legin/fed/decret/1970-1979/decreto-77107-4-fevereiro1976-425615-publicacaooriginal-1-

pe.html\#: :text=Disp\%C3\%B5e\%20sobre\%20a\%20edi\%C3\%A7\%C3\%A3o\%20e,text os $\% 20 \mathrm{e} \% 20 \mathrm{~d} \% \mathrm{C} 3 \% \mathrm{~A} 1 \% 20$ outras\%20provid\%C3\%AAncias. Acesso em: 03, fev. de 2021.

BRASIL. Decreto no 9.099, de 18 de julho de 2017. Dispõe sobre o Programa Nacional do Livro e do Material Didático. Disponível em: https://www2.camara.leg.br/legin/fed/decret/2017/decreto-9099-18-julho-2017-785224publicacaooriginal-153392-pe.html. Acesso em: 03, fev. de 2021.

BRASIL. Decreto-Lei no 1.006, de 30/12/38. Estabelece as condições de produção, importação e utilização do livro didático. Disponível em:

https://www2.camara.leg.br/legin/fed/declei/1930-1939/decreto-lei-1006-30-dezembro1938-350741-publicacaooriginal-1-pe.html. Acesso em: 03, fev. de 2021.

BRASIL. Decreto-Lei $\mathbf{n}^{\mathbf{0}} \mathbf{8 . 4 6 0}$, de 26/12/45. Consolida a legislação sobre as condições de produção, importação e utilização do livro didático. Disponível em:

https://www2.camara.leg.br/legin/fed/declei/1940-1949/decreto-lei-8460-26-dezembro1945-416379-publicacaooriginal-1-pe.html\#: :text=Veja\%20tamb\%C3\%A9m\%3A-

,DECRETO\%2DLEI\%20N\%C2\%BA\%208.460\%2C\%20DE\%2026\%20DE\%20DEZE MBRO\%20DE\%201945,e\%20utiliza\%C3\%A7\%C3\%A3o\%20do\%20livro\%20did\%C3 $\%$ A1tico.\&text $=2 \% \mathrm{C} 2 \% \mathrm{BA} \% 20 \mathrm{Para} \% 20$ os $\% 20$ efeitos $\% 20 \mathrm{da}$, livros $\% 20 \mathrm{de} \% 20$ leitura $\% 20$ de\%20classe. Acesso em: 03, fev. de 2021.

BRASIL. Decreto-Lei $\mathbf{n}^{\circ}$ 93, de 21 de dezembro de 1937. Cria o Instituto Nacional do Livro. Disponível em: http://www.planalto.gov.br/ccivil_03/decreto-lei/19371946/del093.htm\#: :text=Cria\%20o\%20Instituto\%20Nacional\%20do,180\%20da\%20C onstitui\%C3\%A7\%C3\%A3o. Acesso em: 12, mar. de 2021.

BRASIL. Lei de Diretrizes e Bases da Educação. Lei n 9394/1996. Disponível em: https://www.planalto.gov.br/ccivil_03/Leis/L9394.htm. acesso em: 04, fev. de 2021.

CALDART, Roseli Salete; 2008. Sobre Educação do Campo. In: SANTOS, C. A. (Org.). Por uma Educação do Campo: Campo - Políticas Públicas - Educação. Brasília, DF: INCRA; MDA, 2008. p. 67- 86.

CARNEIRO, Maria Helena da Silva; SANTOS, Wildson Luiz. Livro Didático de Ciências: Fonte de informação ou apostila de exercícios. In: Contexto e Educação: Ano 21. Julho/dezembro, Ijuí: Editora Unijuí. 2006. 
FONEC. Manifesto à Sociedade Brasileira. Brasília- DF. 2012. Disponível em: http://www.gepec.ufscar.br/publicacoes/documentos/forum-nacional-de-educacao-docampo-manifesto-a.pdf/view. Acesso em: 28 mar. 2021.

FUNDO NACIONAL DE DESENVOLVIMENTO DA EDUCAÇÃO. Disponível em: http://www.fnde.gov.br/programas/livro-didatico/livro-didatico-historico. Acesso em: 07, fev. de 2021.

GUIA DE LIVROS DIDÁTICOS: PNLD Campo 2013: Guia de Livros. - Brasília: Ministério da Educação, Secretaria de Educação Continuada, Alfabetização, Diversidade e Inclusão, 2012. 57 p.

Informes PNLD 2018. Disponível em: http://www.fnde.gov.br/programas/programasdo-livro/livro-didatico/informe-pnld. acesso em: 30, jan. de 2021.

LIBÂNEO, Didática: velhos e novos tempos. Edição do Autor, maio de 2002.

MINISTÉRIO DA EDUCAÇÃO. Resolução n 15, de 26 de julho de 2018. Dispõe sobre as normas de conduta no âmbito da execução do Programa Nacional do Livro e do Material Didático .Disponível em: https://www.fnde.gov.br/index.php/acesso-ainformacao/institucional/legislacao/item/11997-resolu\%C3\%A7\%C3\%A3on\%C2\%BA15,-de-26-de-julho-de-2018. Acesso em: 03, fev. de 2021.

MINISTÉRIO DA EDUCAÇÃO. Resolução/CD/FNDE n 40, de 26 de julho de 2011. Dispõe sobre o Programa Nacional do Livro Didático do Campo (PNLD Campo) para as escolas do campo.Disponível em: https://www.fnde.gov.br/acesso-ainformacao/institucional/legislacao/item/3463-resolu\%C3\%A7\%C3\%A3o-cd-fnden\%C2\%BA-40-de-26-de-julho-de-

2011\#: :text=Disp\%C3\%B5e\%20sobre\%20o\%20Programa\%20Nacional,\%2C\%20208 $\% 2 \mathrm{C} \% 20211 \% 20 \mathrm{e} \% 20213$.

PARANÁ. Secretaria de Estado da Educação. Diretrizes Curriculares da Rede Pública de Educação Básica do Estado do Paraná: Educação do Campo. Curitiba: SEED, 2006.

Programas do Livro. Disponível em: http://www.fnde.gov.br/. acesso em: 12, mar. de 2021.

Resolução/CD/FNDE no 40, de 26 de julho de 2011. Disponível em: http://www.fnde.gov.br/acesso-a-informacao/institucional/legislacao/item/3463 resolu\%C3\%A7\%C3\%A3o-cd-fnde-n\%C2\%BA-40-de-26-de-julho-de-2011. acesso em: 30, ago. de 2020.

SANTOS, Vanessa dos Anjos dos ; MARTINS, Liziane . A IMPORTÂNCIA DO LIVRO DIDÁTICO. Candombá - Revista Virtual, v. 7, n. 1, p. 20-33, jan - dez 2011.

VIEIRA, Edilaine Aparecida. LIVROS DIDÁTICOS PARA ESCOLAS DO CAMPO:

APROXIMAÇÕES A PARTIR DO PNLD CAMPO-2013. Curitiba, Paraná. 158 f. Disponível em: 
https://www.prppg.ufpr.br/siga/visitante/trabalhoConclusaoWS?idpessoal=7275\&idpro grama $=40001016001 \mathrm{P} 0 \&$ anobase $=2018 \& i d t c=1353$. Acesso em: 10 de abr. de 2021 .

Recebido em: 01/06/2021

Aprovado em: 20/06/2021

Publicado em: 30/06/2021 